\title{
Giant cell arteritis with cervical radiculopathy mimicking polymyalgia rheumatica and elderly-onset rheumatoid arthritis: a case report
}

\author{
Akihiko Nakabayashi ${ }^{1,2^{*}}$, Hiroki Ikai ${ }^{3}$ and Yoshinori Katada ${ }^{4}$
}

\begin{abstract}
Background: Giant cell arteritis has a wide variety of clinical symptoms, one of them being cervical radiculopathy, which mainly involves the $C 5$ nerve root. If the patient does not develop typical clinical symptoms of giant cell arteritis but has $C 5$ radiculopathy, it may be misdiagnosed as polymyalgia rheumatica or elderly-onset rheumatoid arthritis due to old age, high serum inflammatory markers, and difficulty in raising both upper limbs.

Case presentation: A 72-year-old Japanese man with a month-long history of dyspnea on exertion and with difficulty in raising both upper limbs was referred to our hospital because of elevated serum C-reactive protein (12.62 mg/dL). He had no typical symptoms of giant cell arteritis such as headache, jaw claudication, visual loss, and fever. The patient tested negative for rheumatoid factor and anti-cyclic citrullinated peptide antibody, and matrix metalloproteinase-3 was within the normal range $(54.3 \mathrm{ng} / \mathrm{mL})$. Musculoskeletal ultrasound examination showed absence of tenosynovitis, bursitis, and synovitis, and the patient did not meet the classification criteria of polymyalgia rheumatica or rheumatoid arthritis; hence, those two diseases were unlikely. A precise neurological examination suggested bilateral $\mathrm{C} 5$ and $\mathrm{C} 6$ anterior radiculopathy and left C4 radiculopathy. Since cervical magnetic resonance imaging showed no mechanical causality, cervical radiculopathy of unknown origin was suggested. Fluorodeoxyglucose positron emission tomography/computed tomography revealed increased fluorodeoxyglucose lineal uptake along the vessel walls, including temporal arteries, vertebral arteries, and axillary arteries. Results of the biopsy of the left superficial temporal artery were compatible with giant cell arteritis. He was successfully treated with $30 \mathrm{mg}$ of prednisolone, and both upper limbs could be elevated.

Conclusions: If the patient was misdiagnosed with polymyalgia rheumatica or elderly-onset rheumatoid arthritis based on only clinical symptoms and laboratory data, his symptoms might not improve due to insufficient steroid dose and vascular complications may occur later. Although rare, peripheral neuropathy in giant cell arteritis may include cervical radiculopathy. The musculoskeletal ultrasound and precise neurological examination were the turning points for the diagnosis of this case, and making a careful diagnosis using these methods was important.
\end{abstract}

Keywords: Giant cell arteritis, Polymyalgia rheumatica, Elderly-onset rheumatoid arthritis, Cervical radiculopathy, Musculoskeletal ultrasound, Neurological examination

\footnotetext{
*Correspondence: aatm5314@ommc-hp.jp

${ }^{2}$ Department of Rheumatology and Allergology, National Hospital

Organization Osaka Minami Medical Center, 2-1 Kidohigashi,

Kawachinagano, Osaka 586-8521, Japan

Full list of author information is available at the end of the article
}

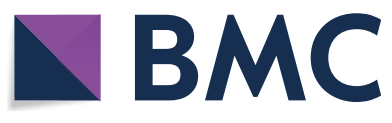
permits use, sharing, adaptation, distribution and reproduction in any medium or format, as long as you give appropriate credit to the original author(s) and the source, provide a link to the Creative Commons licence, and indicate if changes were made. The images or other third party material in this article are included in the article's Creative Commons licence, unless indicated otherwise in a credit line to the material. If material is not included in the article's Creative Commons licence and your intended use is not permitted by statutory regulation or exceeds the permitted use, you will need to obtain permission directly from the copyright holder. To view a copy of this licence, visit http://creativecommons.org/licenses/by/4.0/. The Creative Commons Public Domain Dedication waiver (http://creativeco mmons.org/publicdomain/zero/1.0/) applies to the data made available in this article, unless otherwise stated in a credit line to the data. 


\section{Background}

Giant cell arteritis (GCA) is a chronic systemic vasculitis that occurs in people older than 50 years and generally affects large- and medium-sized arteries. GCA has a wide variety of symptoms such as headache, jaw claudication, visual loss, and systemic manifestations (anorexia, asthenia, malaise, myalgia, arthralgia, weight loss, and so on), but neurological symptoms may also occur [1]. GCA neuropathy is divided into central and peripheral neuropathy, and peripheral neuropathy occurs at a frequency of $1.1-14 \%$ [2-4]. However, radiculopathy is extremely rare in GCA patients with neuropathy [5]. Preferential involvement of the $\mathrm{C} 5$ nerve roots is also reported in GCA patients with radiculopathy $[5,6]$. Because the deltoid, pectoralis major, and supraspinatus muscles are innervated by the $\mathrm{C} 5$ nerve, it is difficult to raise both upper limbs when this nerve is affected. Therefore, if the patient has no typical clinical symptoms of GCA but has C5 radiculopathy, it may be misdiagnosed as polymyalgia rheumatica (PMR) or elderly-onset rheumatoid arthritis (EORA) due to old age, high serum inflammatory markers, and difficulty in raising both upper limbs.

Herein, we report a case of GCA with cervical radiculopathy presenting clinical symptoms similar to those of PMR or EORA, whose diagnostic turning point was musculoskeletal ultrasound examination and precise neurological examination.

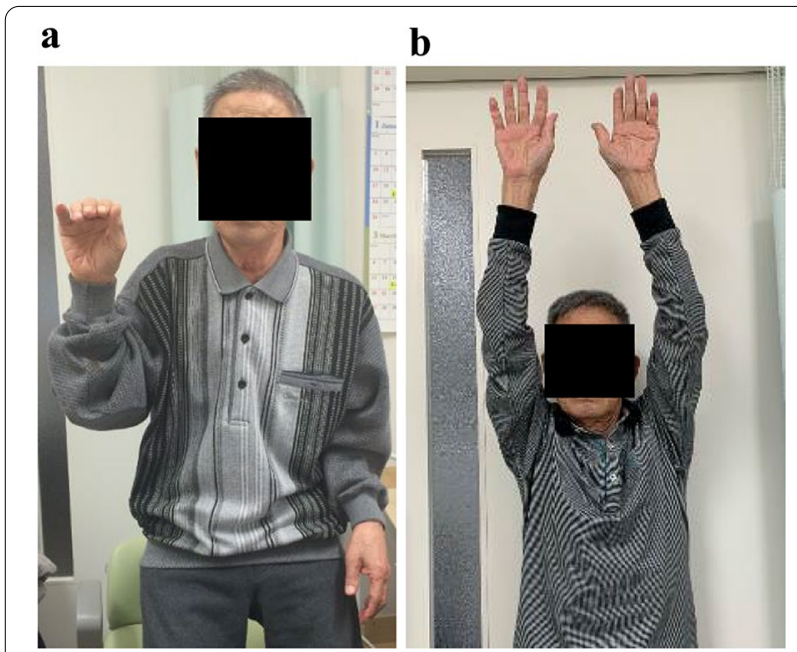

Fig. 1 Clinical course of the patient. a The upper right limb could not be elevated to the shoulder level, whereas the upper left limb could not be elevated at all before treatment. b Both upper limbs could be completely elevated 4 years and 8 months after treatment
Table 1 Laboratory data on admission

\begin{tabular}{|c|c|}
\hline \multicolumn{2}{|l|}{ Complete blood cell } \\
\hline 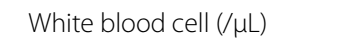 & 10,240 \\
\hline Red blood cell $(/ \mu \mathrm{L})$ & $3.4 \times 10^{6}$ \\
\hline Hemoglobin (g/dL) & 10.4 \\
\hline Platelet $(/ \mu \mathrm{L})$ & $79.5 \times 10^{4}$ \\
\hline \multicolumn{2}{|l|}{ Coagulation test } \\
\hline APTT (second) & 44.5 \\
\hline PT-INR & 1.28 \\
\hline \multicolumn{2}{|l|}{ Biochemistry } \\
\hline $\mathrm{HbA1c}(\%)$ & 6.9 \\
\hline BUN (mg/dL) & 18.5 \\
\hline $\mathrm{Cr}(\mathrm{mg} / \mathrm{dL})$ & 0.80 \\
\hline eGFR (mL/minute/1.73 m²) & 72.57 \\
\hline $\mathrm{Na}(\mathrm{mEq} / \mathrm{L})$ & 137 \\
\hline $\mathrm{K}(\mathrm{mEq} / \mathrm{L})$ & 5.1 \\
\hline $\mathrm{Cl}(\mathrm{mEq} / \mathrm{L})$ & 98 \\
\hline AST (U/L) & 78 \\
\hline $\operatorname{ALT}(U / L)$ & 68 \\
\hline $\mathrm{ALP}(\mathrm{U} / \mathrm{L})$ & 568 \\
\hline LDH (U/L) & 359 \\
\hline CK (U/L) & 52 \\
\hline T-Bil (mg/dL) & 0.47 \\
\hline $\mathrm{TP}(\mathrm{g} / \mathrm{dL})$ & 8.1 \\
\hline Alb (g/dL) & 2.3 \\
\hline ESR (mm/hour) & 31 \\
\hline \multicolumn{2}{|l|}{ Immunochemistry } \\
\hline CRP (mg/dL) & 13.99 \\
\hline $\operatorname{lgG}(\mathrm{mg} / \mathrm{dL})$ & 2744 \\
\hline ANA & $<40$ \\
\hline Anti-SS-A Ab (U/mL) & 0.6 \\
\hline $\mathrm{RF}(\mathrm{U} / \mathrm{mL})$ & 10.6 \\
\hline $\mathrm{ACPA}(\mathrm{U} / \mathrm{L})$ & 0.5 \\
\hline MMP-3 (ng/mL) & 54.3 \\
\hline $\mathrm{C} 3(\mathrm{mg} / \mathrm{dL})$ & 174.1 \\
\hline $\mathrm{C} 4(\mathrm{mg} / \mathrm{dL})$ & 43.8 \\
\hline $\mathrm{CH} 50(\mathrm{U} / \mathrm{mL})$ & 106.7 \\
\hline MPO-ANCA (IU) & $<0.5$ \\
\hline PR3-ANCA (IU) & 0.6 \\
\hline
\end{tabular}

APTT, activated partial thromboplastin time; PT-INR, prothrombin timeinternational normalized ratio; HbA1c, hemoglobin A1c; BUN, blood urea nitrogen; $\mathrm{Cr}$, creatinine; eGFR, estimated glomerular filtration rate; $\mathrm{Na}$, sodium; $\mathrm{K}$, potassium; $\mathrm{Cl}$, chlorine; AST, aspartate aminotransferase; ALT, alanine aminotransferase; ALP, alkaline phosphatase; LDH, lactate dehydrogenase; CK, creatine kinase; T-Bil, total bilirubin; TP, total protein; Alb, albumin; ESR erythrocyte sedimentation rate; CRP, C-reactive protein; IgG, immunoglobulin G; ANA, antinuclear antibody; Anti-SS-A Ab, anti-SS-A antibody; RF, rheumatoid factor; ACPA, anti-cyclic citrullinated peptide antibody; MMP-3, matrix metalloproteinase-3; $\mathrm{C}$, complement component $3 ; \mathrm{C} 4$, complement component 4; $\mathrm{CH} 50,50 \%$ hemolytic unit of complement; MPO-ANCA myeloperoxidase-anti-neutrophil cytoplasmic antibody; PR3-ANCA, proteinase3-anti-neutrophil cytoplasmic antibody 
Table 2 Polymyalgia rheumatica classification criteria scoring algorithm—required criteria: age $\geq 50$ years, bilateral shoulder aching, abnormal C-reactive protein level, and/or erythrocyte sedimentation rate

\begin{tabular}{lcc}
\hline & Points without US (0-6) & $\begin{array}{c}\text { Points } \\
\text { with US } \\
\text { (0-8) }\end{array}$ \\
\hline $\begin{array}{l}\text { Morning stiffness duration }>45 \text { minutes } \\
\text { Hip pain or limited range of motion }\end{array}$ & 2 & 2 \\
Absence of RF or ACPA & 1 & 2 \\
Absence of other joint involvements & 1 & 2 \\
$\begin{array}{l}\text { At least one shoulder with subdeltoid bursitis and/or biceps tenosynovitis and/or glenohumeral synovitis } \\
\text { (either posterior or axillary), and at least one hip with synovitis and/or trochanteric bursitis }\end{array}$ & 1 \\
Both shoulders with subdeltoid bursitis, biceps tenosynovitis, or glenohumeral synovitis & NA & 1 \\
\hline
\end{tabular}

An individual with a score of $\geq 4$ is categorized as having PMR in the algorithm without US, and an individual with a score of $\geq 5$ is categorized as having PMR in the algorithm with US

PMR, polymyalgia rheumatica; CRP, C-reactive protein; ESR, erythrocyte sedimentation rate; US, ultrasonography; RF, rheumatoid factor; ACPA, anti-cyclic citrullinated peptide antibody; NA, not applicable

\section{Case presentation}

A 72-year-old Japanese man with a month-long history of dyspnea on exertion and bilateral shoulder pain gradually presented difficulty in raising both upper limbs. He visited a local doctor and underwent laboratory testing, which revealed an elevated serum $C$-reactive protein (CRP) $(12.62 \mathrm{mg} / \mathrm{dL})$. Hence, he was admitted to our hospital. He was naturally healthy and had no allergies, therefore was not on any medication. He is currently unemployed. His sister has a medical history of rheumatoid arthritis, and his daughter has a medical history of systemic lupus erythematosus. He has smoked 40 cigarettes a day for the past 50 years and does not consume alcohol. On admission, his vital signs were as follows: blood pressure $147 / 90 \mathrm{mmHg}$, pulse 110 beats/minute, respiratory rate 12 breaths/minute, and $\mathrm{SpO}_{2} 98 \%$ (room air). He had no headache, jaw claudication, visual loss, or fever. Tenderness in the bilateral temporal arteries was absent, whereas mild tenderness was observed in both shoulders. The upper right limb could not be elevated to shoulder level, whereas the upper left limb could not be elevated at all (Fig. 1a). A physical examination revealed no abnormalities other than those mentioned above. The laboratory tests revealed an increase in CRP and erythrocyte sedimentation rate (ESR) levels $(13.99 \mathrm{mg} / \mathrm{dL}$ and $31 \mathrm{~mm} /$ hour, respectively). Both rheumatoid factor (RF) and anti-cyclic citrullinated peptide antibody (ACPA) were negative, and the matrix metalloproteinase-3 (MMP-3) level remained normal $(54.3 \mathrm{ng} / \mathrm{mL})$. Antinuclear antibody and anti-SSA antibody were also negative (Table 1). PMR and EORA were considered as differential diagnoses. However, PMR was unlikely as there were no signs of tenosynovitis and bursitis in both shoulders on musculoskeletal ultrasound examination. Moreover, the total score was 3 points and did not meet the 2012
Provisional Classification Criteria for Polymyalgia Rheumatica ("absence of RF or ACPA": 2 points, "absence of other joint involvement": 1 point; Table 2) [7]. EORA was also unlikely because both RF and ACPA were negative, and there were no signs of synovitis on musculoskeletal ultrasound examination. Moreover, the total score was 2 points and did not meet the 2010 Rheumatoid arthritis classification criteria ("joint involvement": 1 point, "acute-phase reactants": 1 point; Table 3) [8]. Since he did not complain of pain even if both upper limbs were passively lifted, neurological disease or muscle disease was considered. Precise neurological examination revealed that there was absence of sensory impairment, but deep tendon reflexes were present in bilateral triceps and the lower limbs, except for bilateral biceps and brachioradialis reflexes. Muscle strength was evaluated by conducting a manual muscle test. The muscle strength of the biceps brachii, brachioradialis, supinator teres, deltoid, pectoralis major, supraspinatus, and infraspinatus decreased predominantly on the left side (Table 4). Ultrasonographic examination showed absence of movement in the left diaphragm during breathing. Hence, bilateral C5 and $\mathrm{C} 6$ radicular involvement (the ventral root of spinal nerve) and left $\mathrm{C} 4$ radicular involvement were suspected. Since cervical magnetic resonance imaging showed no mechanical causality, cervical radiculopathy of unknown origin was suggested. Fluorodeoxyglucose positron emission tomography/computed tomography $\left({ }^{18}\right.$ F-FDG PET/ $\mathrm{CT}$ ) revealed increased FDG lineal uptake along the vessel walls, including the temporal arteries, vertebral arteries, axillary arteries, descending aorta, and femoral arteries (Fig. 2). Ultrasound examination showed absence of abnormality in the common carotid arteries, internal carotid arteries, and temporal arteries, but bilateral vertebral arteries were dilated to approximately $8 \mathrm{~mm}$ from 
Table 3 The 2010 American College of Rheumatology/European League Against Rheumatism classification criteria for rheumatoid arthritis

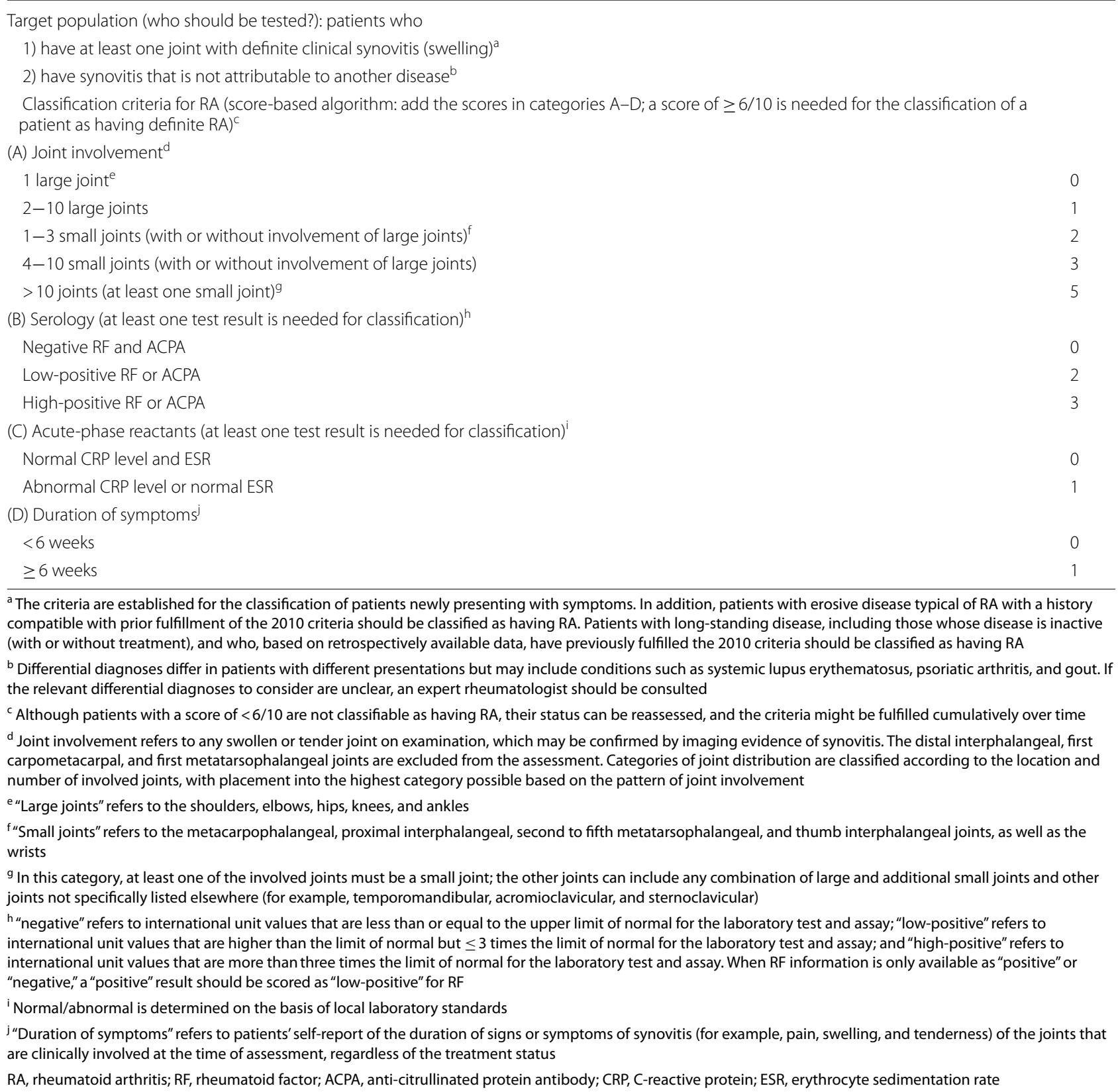

bifurcation to C3 level (Fig. 3a and b). Ultrasound examination did not reveal any abnormality in the temporal artery. However, because ${ }^{18} \mathrm{~F}$-FDG PET/CT revealed FDG uptake in the temporal arteries, a left superficial temporal artery biopsy was conducted that showed histopathological findings compatible with GCA (Fig. 4). Thirty milligrams $(0.6 \mathrm{mg} / \mathrm{kg})$ of oral prednisolone (PSL) was administered, and CRP test turned negative 10 days later. The patient could almost completely elevate both upper limbs almost immediately, his dyspnea on exertion disappeared, and he was discharged 20 days later. Currently, 4 years and 8 months after treatment, he is healthy and the result of CRP test remains negative with $1 \mathrm{mg}$ of PSL (Fig. 1b) (Additional file 1). 
Table 4 Manual muscle test on admission

\begin{tabular}{llll}
\hline & Right & Left & Dominant nerve \\
\hline Biceps brachii & $3 / 5$ & $1 / 5$ & C5-C6 \\
Triceps brachii & $5 / 5$ & $5 / 5$ & C6-C7-C8 \\
Brachioradialis & $5 / 5$ & $1 / 5$ & C5-C6 \\
Supinator teres & $5 / 5$ & $1 / 5$ & C5-C6 \\
Pronator teres & $5 / 5$ & $5 / 5$ & C6-C7 \\
Deltoid & $3 / 5$ & $1 / 5$ & C5-C6 \\
Pectoralis major & $3 / 5$ & $3 / 5$ & C5-C6-C7-C8-T1 \\
Trapezius & $5 / 5$ & $5 / 5$ & C3-C4 \\
Supraspinatus & $3 / 5$ & $1 / 5$ & C5-C6 \\
Infraspinatus & $3 / 5$ & $*$ & C5-C6 \\
Rhomboids & $5 / 5$ & $5 / 5$ & C4-C5 \\
Latissimus dorsi & $5 / 5$ & $5 / 5$ & C6-C7-C8 \\
\hline
\end{tabular}

\section{C, cervical; $T$, thoracic}

* We could not assess the patient's left infraspinatus muscle strength as he was unable to get the correct limb position

\section{Discussion and conclusions}

We reported a case of GCA with cervical radiculopathy presenting clinical symptoms similar to those of PMR or EORA.

PMR is an inflammatory disorder that occurs in elderly people older than 50 years. PMR is characterized by pain in both shoulders, neck, and hip girdle, and morning stiffness of more than 45 minutes. Moreover, nonspecific symptoms such as general fatigue and malaise may be observed. Elevated serum inflammatory markers are a typical feature $[7,9]$.

EORA is also an inflammatory disease that occurs in elderly people older than 60 years, and it is prevalent in men, has acute onset, involves the large and proximal joints, and has less RF positivity $[10,11]$. In this case, although PMR and EORA were initially suspected

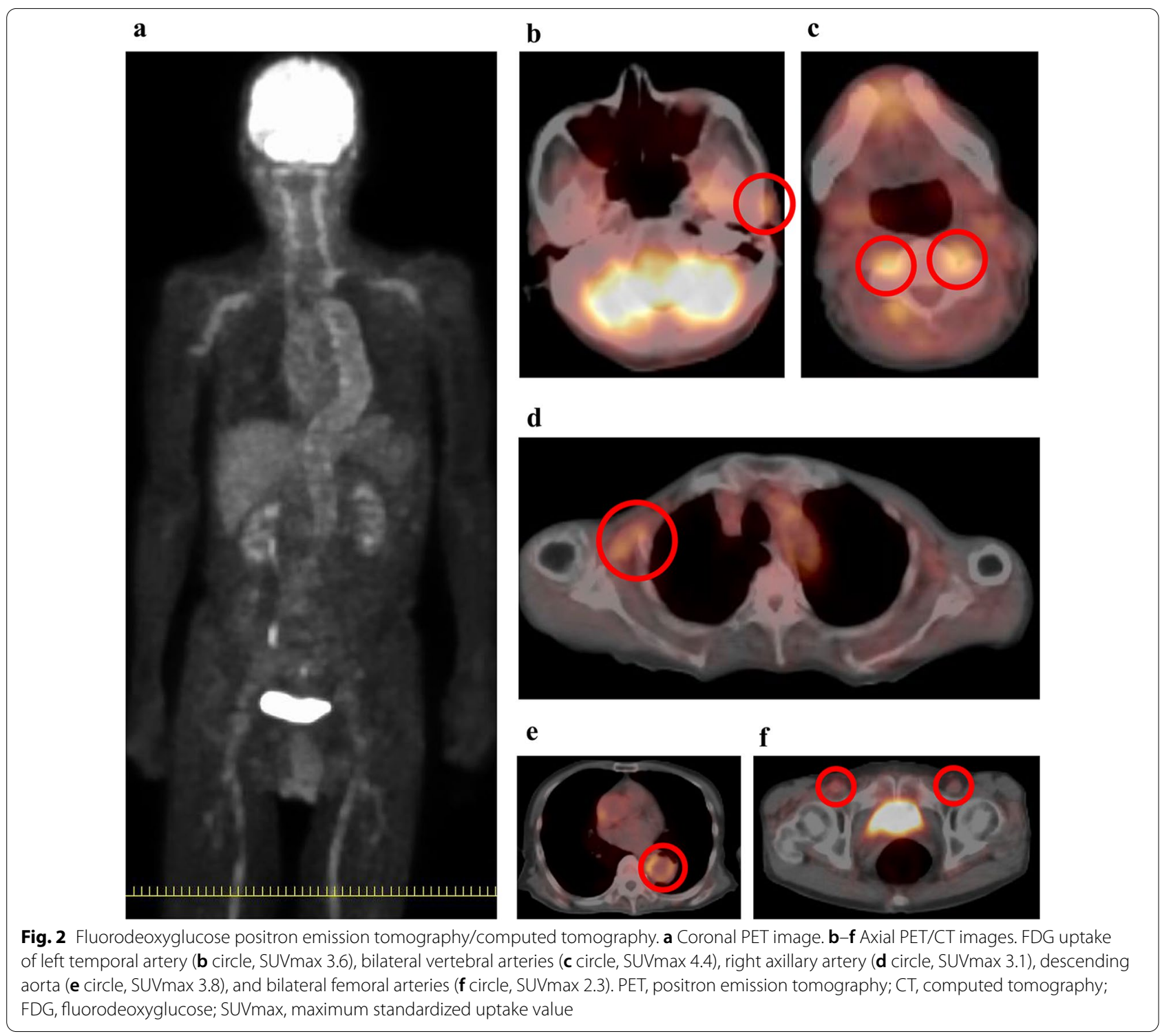


$\mathbf{a}$

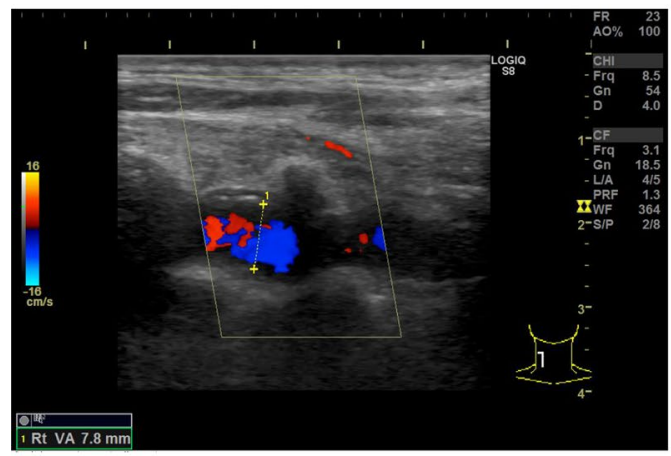

c

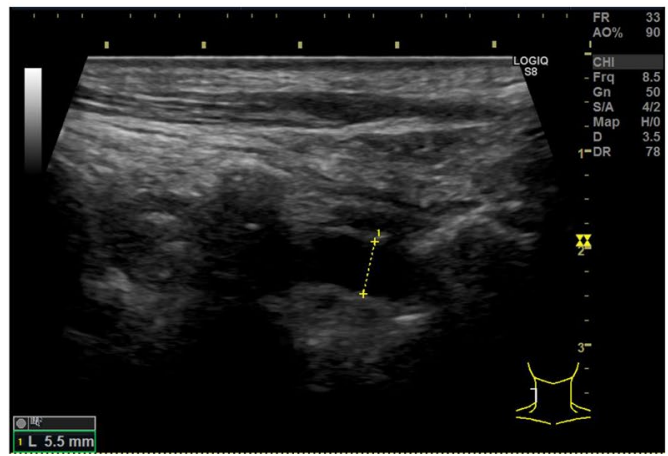

b

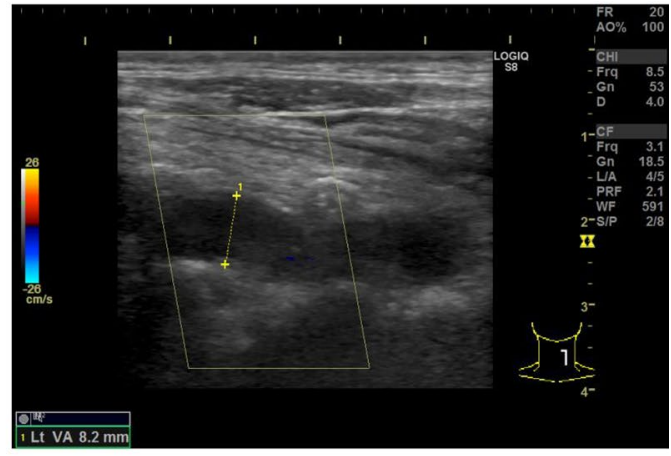

d

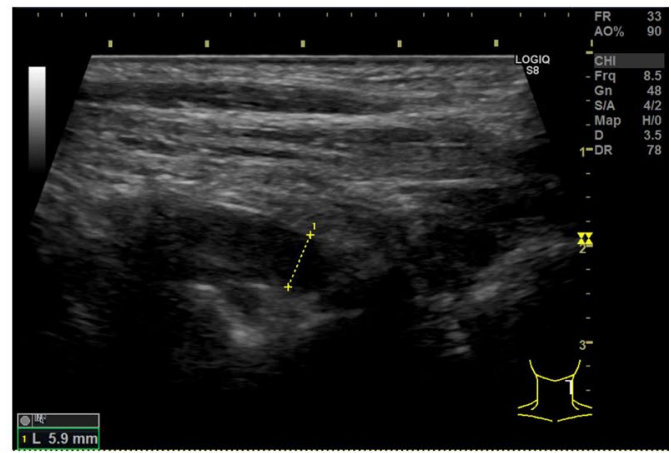

Fig. 3 Ultrasound findings of bilateral vertebral arteries before and after treatment. Bilateral vertebral arteries were observed from bifurcation to C3 level by ultrasound. Before treatment, those were dilated to approximately $8 \mathrm{~mm}$ on all levels. a Right vertebral artery. b Left vertebral artery. Four years and 8 months after treatment, the above-mentioned arteries decreased to approximately $5.5 \mathrm{~mm}$ on all levels. $\mathbf{c}$ Right vertebral artery. $\mathbf{d}$ Left vertebral artery

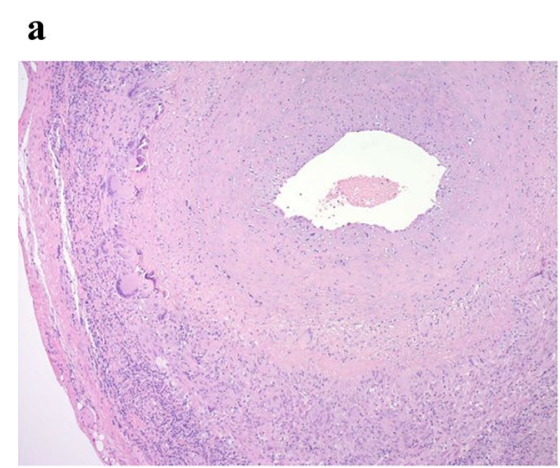

b

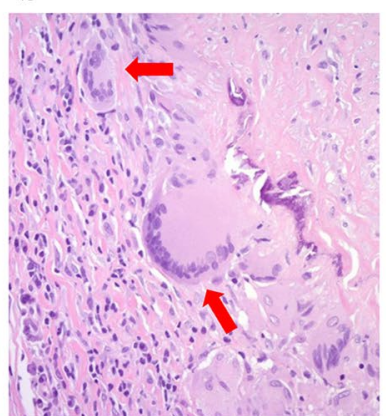

\section{c}

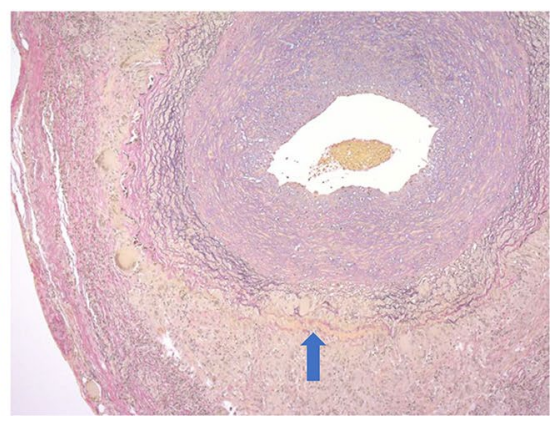

Fig. 4 Histopathology of left superficial temporal artery biopsy. $\mathbf{a}$ and $\mathbf{b}$ Number of inflammatory cell infiltrates mainly in the media and sporadic multinucleated giant cells (red arrows) with intimal hyperplasia and vascular occlusion (hematoxylin-eosin staining: a, $\times 50 ; \mathbf{b}, \times 200$ ). $\mathbf{c}$ Fragmentation of the internal elastic lamina (blue arrow) (Elastica van Gieson staining: $\mathbf{c}, \times 50$ )

because of old age, pain in both shoulders, difficulty in raising both upper limbs, and increased inflammatory response, the possibility of the incidence of these diseases was unlikely based on musculoskeletal ultrasound findings and each classification criteria. A precise neurological examination suggested cervical radiculopathy of unknown origin, and subsequent ${ }^{18}$ F-FDG PET/CT findings suggested GCA. The biopsy of the left superficial temporal artery confirmed the diagnosis of GCA.

Recently, a characteristic ${ }^{18}$ F-FDG PET/CT finding of PMR has been reported; FDG uptake was observed not only in the shoulder and hip joints but also in the ischial 
tuberosity, spinous process, and so on [9, 12-14]. In this case, the lack of uptake of FDG in the ischial tuberosity and spinous process did not indicate PMR. Similarly, because FDG was not taken up in the joints at all, EORA could be ruled out.

As the mechanism of radiculopathy in GCA, vasculitis of the vertebral arteries could reduce blood flow in the radicular arteries, which supply blood to the spinal nerve roots [15]. Moreover, prior autopsy reports confirmed vasculitis in the radicular arteries rather than in the proximal feeding vessels [16].

In this case, radiculopathy occurred mainly in the C5 nerve as previously reported $[5,6]$. The following mechanism has been proposed to explain $\mathrm{C} 5$ nerve dominance. The radicular arteries at the $\mathrm{C} 1-\mathrm{C} 6$ levels receive blood supply from the vertebral arteries, whereas the radicular arteries at the C7-T1 levels receive blood supply from the thyrocervical and costocervical trunks. Therefore, even if vertebral artery vasculitis occurs, the blood flow is relatively maintained at the C7-T1 levels, and radiculopathy is less likely to occur. The radicular arteries at the $\mathrm{C} 1-\mathrm{C} 4$ levels are also compensated by blood flow from the anterior spinal artery; hence, the $\mathrm{C} 5$ and $\mathrm{C} 6$ nerve roots are susceptible to radiculopathy [17].

It has also been reported that the muscles that control the $\mathrm{C} 1-\mathrm{C} 3$ nerves are located in the head and neck, and even if radiculopathy occurs in that area, it is difficult to establish a diagnosis [5]. Andrzejczak et al. reported the sources of vascularization of the brachial plexus using six autopsy cadavers. The vertebral and ascending cervical arteries were the most common sources of blood flow to the C5 and C6 nerve roots (both 35.29\%). The subclavian artery predominantly supplied blood flow to the $\mathrm{C} 7$ nerve roots $(66.67 \%)$ and the vertebral artery $(8.33 \%)$. The deep cervical artery was the predominant source of blood flow to the $\mathrm{C} 8$ and $\mathrm{T} 1$ nerve roots $(64.71 \%)$, but the vertebral artery is not a source of blood flow (0\%). Therefore, C5 and $\mathrm{C6}$ radiculopathy may be more likely to occur if vertebral artery vasculitis occurs; the blood vessels supplying the $\mathrm{C} 1-\mathrm{C} 4$ nerve roots are not described [18].

In this case, both upper limbs can be raised relatively immediately after treatment, and the treatment response is very similar to that of PMR. If radiculopathy occurs only due to ischemia as previously reported, the mechanism behind how both upper limbs can be elevated immediately after treatment remains unknown.

In this case, the vertebral arteries were among the affected blood vessels, and patient's ultrasound revealed that the luminal diameter of bilateral vertebral arteries was dilated to approximately $8 \mathrm{~mm}$ before treatment and improved to approximately $5.5 \mathrm{~mm} 4$ years and 8 months after treatment (Fig. 3). The luminal diameter of the vertebral artery was reported to be $3.6 \pm 0.4 \mathrm{~mm}$ (mean \pm SD) in healthy adults aged $60-85$ years on ultrasound [19]. Anatomically, the vertebral arteries generally enter the transverse foramen at the C6 level and ascend, and the vertebral arteries and the cervical nerve roots are very close to each other at the C1-C6 levels. Therefore, the spread of inflammation of the vertebral artery can cause radiculopathy; once the inflammation improves after steroid treatment, the weakness in the upper limbs will also improve. However, this hypothesis is only speculative and needs to be evaluated in the future.

If this case was misdiagnosed as PMR or EORA based only on the clinical symptoms and laboratory data, the patient is expected to demonstrate CRP positivity, difficulty in raising both upper limbs, and dyspnea on exertion due to insufficient steroid treatment. If the patient continues to receive inadequate treatment, vascular complications may occur later. Therefore, it is essential to recognize that peripheral neuropathy of GCA can be manifested with radicular symptoms commonly affecting C5 nerve root. If the typical clinical symptoms of GCA are absent, then the clinical symptoms are similar to those of PMR or EORA. The musculoskeletal ultrasound and precise neurological examination were the turning points for the diagnosis of this case, and making a careful diagnosis using these methods was thought to be important.

\section{Abbreviations}

GCA: Giant cell arteritis; PMR: Polymyalgia rheumatica; EORA: Elderly-onset rheumatoid arthritis; CRP: C-reactive protein; ESR: Erythrocyte sedimentation rate; RF: Rheumatoid factor; ACPA: Anti-cyclic citrullinated peptide antibody; MMP-3: Matrix metalloproteinase-3; ${ }^{18}$ F-FDG PET/CT: Fluorodeoxyglucose positron emission tomography/computed tomography; PSL: Prednisolone.

\section{Supplementary Information}

The online version contains supplementary material available at https://doi. org/10.1186/s13256-021-03107-7.

Additional file 1: CARE flow diagram. Initial and Follow-up Patient Visit Documentation.

Acknowledgements

The authors would like to thank Enago (www.enago.jp) for the English language review.

\section{Authors' contributions}

All authors took care of the patient. AN prepared the manuscript. YK reviewed and revised the manuscript. All authors read and approved the final manuscript.

\section{Funding}

This research did not receive any specific grant from funding agencies in the public, commercial, or not-for-profit sectors.

Availability of data and materials Not applicable. 


\section{Declarations}

\section{Ethics approval and consent to participate}

This study has not been approved by the hospital committee to report this case report. However, the person in charge of the hospital verbally agreed. Written consent from the patient was obtained for participation.

\section{Consent for publication}

Written informed consent was obtained from the patient for publication of this case report and any accompanying images. A copy of the written consent is available for review by the Editor-in-Chief of this journal.

\section{Competing interests}

The authors declare that they have no competing interests.

\section{Author details}

'Department of Nephrology, Diabetology, and Rheumatology, Sakai City Medical Center, Ebaraji-cho 1-1-1, West Ward, Sakai, Osaka 593-8304, Japan

${ }^{2}$ Department of Rheumatology and Allergology, National Hospital Organization Osaka Minami Medical Center, 2-1 Kidohigashi, Kawachinagano, Osaka 586-8521, Japan. ${ }^{3}$ Department of Rheumatology, Japan Organization of Occupational Health and Safety Chubu Rousai Hospital, 1-10-6 Koumei Minato-ku, Nagoya, Aichi 586-8521, Japan. ${ }^{4}$ Department of Respiratory Medicine and Clinical Immunology, Suita Municipal Hospital, 5-7 Kishibeshinmachi, Suita, Osaka 564-8567, Japan.

Received: 24 June 2020 Accepted: 10 September 2021

Published online: 20 October 2021

\section{References}

1. Kawasaki A, Purvin V. Giant cell arteritis: an updated review. Acta Ophthalmol. 2009;87:13-32

2. Meadows S. Temporal or giant cell arteritis. Proc R Soc Med. 1966;59:329-34.

3. Hollenhorst RW, Brown JR, Wagener HP, Shick RM. Neurologic aspects of temporal arteritis. Neurology. 1960;10:490-8.

4. Caselli RJ, Daube JR, Hunder GG, Whisnant JP. Peripheral neuropathic syndromes in giant cell (temporal) arteritis. Neurology. 1988;38:685-9.

5. Soubrier M, Dubost JJ, Tournadre A, Deffond D, Clavelou P, Ristori JM. Cervical radiculopathy as a manifestation of giant cell arteritis. Jt Bone Spine. 2002;69:316-8.

6. Duval F, Lacoste I, Galli G, Chaumont H, Solé G, Léger F, et al. Acute brachial radiculoplexopathy and giant cell arteritis. Neurologist. 2018;23:23-8

7. Dasgupta B, Cimmino MA, Kremers HM, Schmidt WA, Schirmer M, Salvarani C, et al. 2012 provisional classification criteria for polymyalgia rheumatica: a European League Against Rheumatism/American College of Rheumatology collaborative initiative. Arthritis Rheum. 2012:64:943-54

8. Aletaha D, Neogi T, Silman AJ, Funovits J, Felson DT, Bingham CO, et al. 2010 rheumatoid arthritis classification criteria: an American College of Rheumatology/European League Against Rheumatism collaborative initiative. Ann Rheum Dis. 2010;69:1580-8.

9. González-Gay MA, Matteson EL, Castañeda S. Polymyalgia rheumatica. Lancet. 2017:390:1700-12.

10. Serhal L, Lwin MN, Holroyd C, Edwards CJ. Rheumatoid arthritis in the elderly: characteristics and treatment considerations. Autoimmun Rev. 2020;19: 102528. https://doi.org/10.1016/j.autrev.2020.102528.

11. Yazici Y, Paget SA. Elderly-onset rheumatoid arthritis. Rheum Dis Clin North Am. 2000;26:517-26.

12. Takahashi H, Yamashita H, Kubota K, Miyata Y, Okasaki M, Morooka M, et al. Differences in fluorodeoxyglucose positron emission tomography/computed tomography findings between elderly onset rheumatoid arthritis and polymyalgia rheumatica. Mod Rheumatol. 2015;25:546-51.

13. Sondag M, Guillot X, Verhoeven F, Blagosklonov O, Prati C, Boulahdour H, et al. Utility of 18F-fluoro-dexoxyglucose positron emission tomography for the diagnosis of polymyalgia rheumatica: a controlled study. Rheumatology. 2016;55:1452-7.

14. Blockmans D, De Ceuninck L, Vanderschueren S, Knockaert D, Mortelmans L, Bobbaers H. Repetitive 18-fluorodeoxyglucose positron emission tomography in isolated polymyalgia rheumatica: a prospective study in 35 patients. Rheumatology. 2007;46:672-7.

15. Sänchez MC, Arenillas Jl, Gutierrez DA, Gutierrez Alonso JL, Alvarez JD. Cervical radiculopathy: a rare symptom of giant cell arteritis. Arthritis Rheum. 1983;26:207-9.

16. Burton EA, Winer JB, Barber PC. Giant cell arteritis of the cervical radicular vessels presenting with diaphragmatic weakness. J Neurol Neurosurg Psychiatry. 1999;67:223-6.

17. Hughes TAT, Wiles CM, Hourihan M. Cervical radiculopathy and bilateral internuclear ophthalmoplegia caused by temporal arteritis. J Neurol Neurosurg Psychiatry. 1994;57:764-5.

18. Andrzejczak A, Kwolczak A, Ciszek B, Wojda-gradowska U. Brachial plexus vascularization-a preliminary study. Acta Clin. 2001;1:111-6.

19. Scheel P, Ruge C, Schöning M. Flow velocity and flow volume measurements in the extracranial carotid and vertebral arteries in healthy adults: reference data and the effects of age. Ultrasound Med Biol. 2000;26:1261-6.

\section{Publisher's Note}

Springer Nature remains neutral with regard to jurisdictional claims in published maps and institutional affiliations.
Ready to submit your research? Choose BMC and benefit from:

- fast, convenient online submission

- thorough peer review by experienced researchers in your field

- rapid publication on acceptance

- support for research data, including large and complex data types

- gold Open Access which fosters wider collaboration and increased citations

- maximum visibility for your research: over 100M website views per year

At $\mathrm{BMC}$, research is always in progress.

Learn more biomedcentral.com/submissions 